\title{
Research on the teaching strategy of foreign Chinese reading based on the characteristics of international school students
}

\author{
Zhang Lan \\ Clearwater Bay school, Hong Kong, Zip code 999077, China \\ landyzhang1989@gmail.com
}

Keywords: International School Students, Languages (Chinese), Education, International courses.

\begin{abstract}
With respect to teaching Chinese as a foreign language, reading class is considered to be a skill training class. Among the whole teaching progress, intermediate reading plays an important role in connecting other teaching courses. Reading has a positive effect on foreign students, and it not only helps students consolidate knowledge which they have learned, but also helps to understand the Chinese culture. Having reading ability can help learners improve their communication competence. Most research objects in teaching Chinese Intermediate Reading are about the students from countries with different native language. The writer finds that for students who speak the same native language, they would have the same habit of learning which influenced by their cognitive features. If the teachers know about these cognitive features, they can take appropriate teaching strategies for the students to help them understand easily. Therefore, the paper is about summarizing the cognitive features of English-speaking students by contrasting the differences of cognitive features between Chinese and English. Then, through the methods of literature research, find the existing teaching insufficiency of Intermediate Reading. For instance, in teaching class, teachers ignore the dominant role of students and reading skills and cultural knowledge are not enough in teaching. For students, they have limited vocabulary and so on. Based on the cognitive features of the students in English-speaking countries and the insufficiency of Intermediate Reading, make some teaching strategies of Chinese Intermediate Reading from vocabulary, sentence and the whole passage.
\end{abstract}

\section{Introduction}

Chinese reading plays an important role in the Chinese language teaching, It is one of the main ways for people to get external information. With the reading amount of materials and reading space increase rapidly for the students in intermediate stage, the interest of students decreased significantly. The students also enhanced the sense of fear [1]. In the teaching of reading, the reading teachers uses a variety of teaching methods to enhance students' interest in learning, and the students also working hard to memorize words and master grammar, but the final effect is not ideal [2]. So it is meaningful to take effective teaching strategies to help students achieve this goal.

The purpose of this research on learning strategies for efficient reading is to provide a basis for effective training and support for the benefit of language learners [3]. The training of such learning strategies involves a lot of preparation, such as raising learners' awareness of learning strategies, selecting appropriate strategies to be practiced and making decisions on approaches to such training [4]. Learning strategies are keys to greater autonomy and more meaningful learning [5]. Although learning strategies are used by students themselves, it is always the teacher's responsibility to help learners realize and understand that there is a wide range and variety of choices of learning strategies for use in the language learning process, and that to make intelligent judgment, informed choices and appropriate implementation are essential in both language teaching and language learning [6].

This paper uses literature and Investigation of two research methods, Shun investigation, the reverse search method, and citation search method, the use of specialized databases, text information and related Web site with comprehensive information to clarify the historical context and 
development trend of the subjective sense of reading teaching strategy of TCSL intermediate [6]. In addition, using the combination of questionnaires and interviews, conduct empirical research, writer did an empirical study of intermediate students in the current colleges and universities in Urumqi, and interviewed the senior reading teacher. The qualitative and quantitative combination of the way to go to collect information in Urumqi, so that this study information with the real situation remained relatively consistent [7]. This essay is divided into six parts, the first part of the research is about the background of Chinese reading, the purpose and significance of this study ,the relevant research literature review. The second part is the theoretical basis of the intermediate reading of the Chinese as a Foreign Language Teaching Strategies [8]. Part three is the definition of the concept. The fourth part is the status and analysis of teaching and learning of Chinese as a Foreign Language Intermediate reading. The fifth part is of the Chinese as a Foreign Language Intermediate reading instruction strategy The sixth part is of the epilogue.

\section{The main theory of learning strategies}

Learning strategies as a more systematic theory, mainly refers to the students to achieve a certain learning objectives and the use of learning methods, skills or rules [9]. Psychologists use the computer to effectively imitate the problem-solving strategy, which in Bruner, the year's "cognitive strategy" based on the formation of the concept of learning strategies, causing great interest in educational psychologists [10]. Researchers reveal the characteristics of learning strategies from different perspectives. Some people think that learning strategies are learners' efforts to improve language skills and social language skills in their target language learning, that is, to incorporate these two abilities into transitional language skills [11]. Language learning strategies are learning language The practice or ideas that are intended to influence the learner's coding process, "and others argue that learning strategies are implicit learning rules that are the process of student learning [12].

Learning strategies can be divided into general learning strategies and subject learning strategies. Language learning strategies are a kind of disciplinary learning strategies, including first language learning strategies, second language learning strategies and foreign language learning strategies [13]. After the 1980s, the study of language learning strategies has been developed rapidly. In their monograph for the first time the learning strategy into the framework of the second language learning theory to study. Based on the cognitive learning theory, they study the learning strategies from the cognitive process of language learning, and discuss the research direction of the learning strategies and how to train the learners to use the learning strategies [14].

Since the 1990s, the study of language learning strategies has continued to develop, and the following studies have focused on the study of language learning strategies and the study of autonomous learning. The training of language learning strategies has become the focus of learning strategies [15]. Researchers of language learning strategies are concerned with the relationship between learning strategies and culture.

Learning strategy system classification. There are many types of classification strategies for learning strategies, which generally include the following: form of expression, user, psychological process, whether the direct role in the learning process, the level of learners, the use of purpose. Oxford's classification framework is considered to be the easiest to understand and accept a classification method [16].

Oxford on the basis of summing up their own and others on the basis of research results, the learning strategy is divided into six categories, three categories for the direct strategy, the other three categories for the indirect strategy. Each category is divided into a number of sub-categories, a total of nineteen categories. Each subclass is divided into a number of learning strategies. Finally, a total of more than sixty learning strategies are listed in Table.1.

Factors that affect the use of learning strategies. Studies have shown that age has a significant impact on the use of learning strategies. Learners' cognitive abilities grow with age, and their cognitive approach grows with age. Changes in cognitive and cognitive styles directly affect the formation and use of learning strategies. 
Table.1 The typical six categories of learning strategues

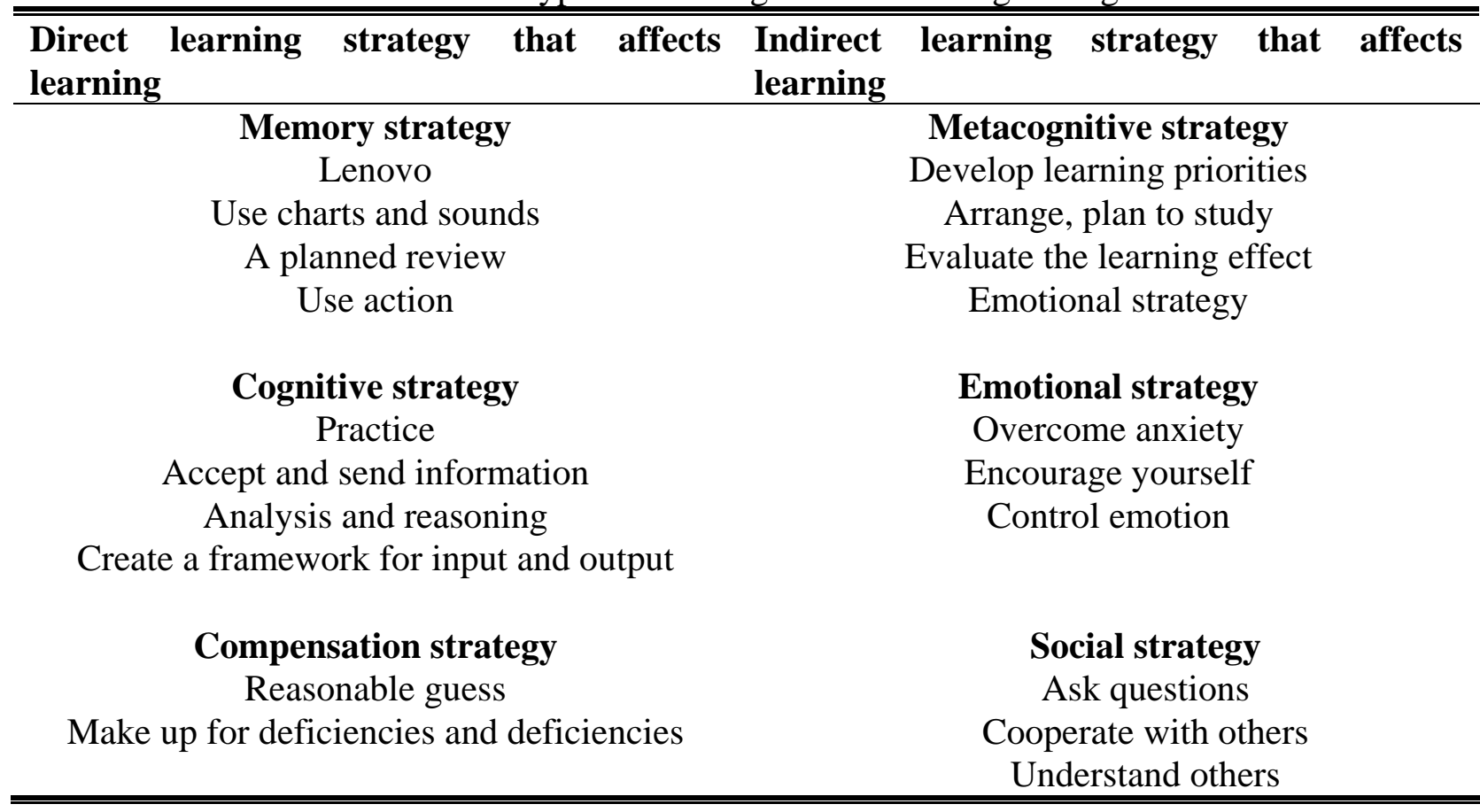

Young children are limited by thinking ability, can only use some simple strategy, and the use of low frequency, while adults can use more complex and more advanced strategy. This is also one of the main reasons why adults are learning in some aspects of language learning such as grammar and vocabulary is faster than children.

Secondly, learners' attitudes and motivations have a significant effect on the use of learning strategies. Studies have shown that learners with positive attitudes and higher motivation have more use of learning strategies and higher frequency of use. In addition, the type of motivation also affects the use and choice of learning strategies. Again, the differences in learners' existing language levels also affect the use and selection of learning strategies. Studies have shown that advanced learners use more learning strategies than beginners, and are more frequently used. At the same level, learners with better grades have more learning strategies than learners with poor grades. Of course, the learner's intellectual and linguistic potential also affects the use of learning strategies.

Finally, the learner's learning environment also affects the use of learning strategies. The learning environment includes teachers' teaching methods, teaching materials, evaluation criteria and assessment methods, the degree of autonomy of students and other cultural influences of learners.

\section{Intermediate Reading Strategies for Chinese as a Foreign Language}

Teaching Chinese as a Foreign Language and Learning Strategies. The teaching of Chinese as a foreign language is an independent discipline. It is the teaching of Chinese as a second language. It is how Chinese people who do not understand Chinese know Chinese in the shortest possible time and master Chinese. The goal of teaching Chinese as a foreign language is to train students to use Chinese to communicate through certain skills training. How to cultivate communicative competence How to transform knowledge into skills How to reflect student-centeredness in teaching? The goal of education is not only "what to learn", but more "how to learn", so study the learning strategy and in teaching Penetration of learning strategies to train students who are good at independent thinking, to achieve better teaching objectives.

Intermediate reading of Chinese as a foreign language. Teaching Chinese as a foreign language is generally divided into three stages: primary, intermediate and advanced. Reading is also divided into three stages. These three stages are different for students to read on the requirements. The intermediate stage focuses on the understanding of words, words and sentences, and the 
intermediate stage focuses on the understanding of the chapter. Therefore, the intermediate stage is the key stage of training and reading skills. It is also the stage of students' ability to transform skills knowledge into ability through reading practice. At this stage of the students to read the learning strategy of training to help students learn the long-term development.

Students have mastered 2000 3000 words, learned Chinese grammar, after primary reading training, with a considerable Chinese reading experience, to understand China's general knowledge of life and cultural common sense, with further improve the speed and difficulty of the conditions. But there are still good training habits of reading, reading anxiety and other issues to eliminate. The purpose of intermediate reading teaching is to use verbal skills training as the core to cultivate the communicative competence of foreign students, which is the purpose of teaching Chinese as a foreign language in the middle and higher stages. Specific to the intermediate Chinese reading class, the purpose of teaching is to cultivate and improve the ability of students to read Chinese written language. It is the basic task of starting from the reading skills, by reading a large number of Chinese written language materials, words, sentences, paragraphs and chapters of the students in a centralized, systematic, targeted training, so that they can be able to learn by analogy reading ability.

It can be seen that intermediate reading is the rule and method that requires students to truly learn to acquire knowledge, and use learning strategies in reading to gain the ability to learn aloud.

The Curriculum Standard in Teaching Chinese as a Foreign Language. "Advanced level curriculum in teaching Chinese as a foreign language" pointed out that intermediate reading teaching content includes:

To overcome the problems of reading, to develop the habit of silent reading. Silent reading from the eyes directly to the Chinese characters symbol to the brain center, eliminating the "symbol meaning" intermediate link - "sound" is the best way to identify Chinese characters, and can quickly by the perception of Chinese characters, the transition to the content Understanding, so as to achieve fast reading, deep understanding, memory prison reading effect.

Train students' ability to master words and words. Students in the reading of the first difficulties encountered is the word, the word off, should be through the identification of Chinese characters and Chinese characters word law teaching, and thus improve the reading speed.

Train students to master the skills of reading long sentences and difficult sentences. If you use the abbreviation to understand the long sentence according to the related words to understand the complex sentence according to the rhetorical characteristics of the sentence, semantic relations, context comprehension difficult sentence.

Train students to grasp the purpose of paragraphs, summarize the contents of the paragraph. The main sentence of the paragraph is a sentence that expresses the thought of the center of the passage, often at the beginning or end of the paragraph, and it is often caught by the main part of the paragraph. The use of some of the hints that indicate the hierarchy and logical relations is often live these words, can help understand the contents of the paragraph.

Train students to master the ability to understand the theme of the article. By analyzing the teaching of the title of the article and looking for the theme of the article, the subject section of the training, so that students can quickly grasp the reading of the central idea of the article.

Introduce the basics of the work. Such as the author's life thought, the writing background of the article. Appropriate teaching of some relevant stylistic knowledge, writing skills and cultural knowledge.

Teaching content mainly reflects the training of reading skills, but the students will not use the skills of the line, so teachers should read the application of learning strategies to guide students to help form an effective reading strategy to improve students' ability to self-learning, and ultimately improve reading ability.

Intermediate reading strategy. To improve the students's reading ability, the effective itermediate reading strategies inluding cognitive reading strategy, metacognitive reading strategy, compensation reading strategy and emotional strategyare presented as follwing: 
Table. 2 Cognitive reading strategy

\begin{tabular}{cl}
\hline \hline Number & \multicolumn{1}{c}{ Specific Strategy } \\
\hline 1 & $\begin{array}{l}\text { Predict the contents of the paragraph or part of the article. } \\
2\end{array}$ \\
3 & $\begin{array}{l}\text { Pay attention to the use of grammar to understand the language structure is not } \\
\text { Take advantage of the article to help comprehensively understand the article. }\end{array}$ \\
4 & $\begin{array}{l}\text { Expand vocabulary and grammar knowledge, improve reading level. } \\
\text { Use the existing knowledge, guess not familiar with the meaning of words and } \\
\text { phrases. }\end{array}$ \\
6 & $\begin{array}{l}\text { Analyze the topic of the article, the link between the subject matter and the } \\
\text { paragraph to enhance understanding. }\end{array}$ \\
9 & $\begin{array}{l}\text { Learn more difficult chapters by splitting longer sentences. } \\
\text { Combine the target language with the mother tongue knowledge to help understand. }\end{array}$ \\
10 & $\begin{array}{l}\text { Describe the relevant arguments by means of diagrams to help you understand the } \\
\text { relationship between words and opinions. }\end{array}$ \\
\hline \hline
\end{tabular}

Table.3 Metacognitive reading strategy

\begin{tabular}{cl}
\hline \hline Number & \\
\hline 1 & Set goals, improve a certain level of learning \\
2 & List the relevant words before reading. \\
3 & To carry out cooperative learning, to help improve their reading skills. \\
4 & Often review and keep progress. \\
5 & Evaluate what you have learned and your performance to enhance your \\
\hline \hline
\end{tabular}

Table.4 Compensation reading strategy

\begin{tabular}{cl}
\hline \hline Number & \multicolumn{1}{c}{ Specific Strategy } \\
\hline 1 & Use the contents of the study, to enhance reading comprehension. \\
3 & Used to take notes to help remember important details. \\
4 & $\begin{array}{l}\text { My reading the contents of the study to improve reading comprehension. } \\
\text { effective memory. }\end{array}$ \\
5 & $\begin{array}{l}\text { Use the body movements to help read the information read. } \\
6\end{array}$ \\
7 & $\begin{array}{l}\text { In the mind to imagine the story of the situation, to help understand the memory read } \\
\text { the article }\end{array}$ \\
8 & Vocabulary in accordance with certain rules for classification, can help clear \\
\hline \hline
\end{tabular}


Table.5 Emotional reading strategy

\begin{tabular}{cl}
\hline \hline Number & \\
\hline 1 & Consciously cultivate interest in reading study. \\
2 & Cultivate positive interest in reading study. \\
3 & And gradually establish the confidence of reading learning. \\
4 & Trying to overcome the shyness and anxiety in reading. \\
5 & Encourage each other in learning. \\
6 & Monitor and control the emotions in learning. \\
7 & In reading study, happy to learn from the students and to help students \\
\hline \hline
\end{tabular}

\section{Teaching Guidance of Reading Learning Strategies in Chinese as a Foreign Language}

The purpose of reading a learning strategy training is to explicitly teach students at what time and for what reason and how to use learning strategies to promote reading, that is, by giving students a direct explanation of how to develop their own strategy system to help students To explore ways to more effectively learn the target language, so that students naturally choose to read learning strategies, to enable students to self-read learning, but also to promote their self-evaluation in learning, rather than always rely on the supervision of teachers. In short, the fundamental purpose of reading learning strategies is to enable students to learn Chinese reading and learning. The role of reading strategy training is that the training of students' reading strategies can lead them to master and apply multiple types of learning strategies throughout the reading process and to use them in a larger context. This will not only improve their learning skills, but also improve their language skills.

The form of learning strategy training. Learning strategy training has always been the focus of study strategy researchers, of which the main patterns are presented as follows. Fig.1 presents A dual-Cop framework for analyzing the perspectives of the administrator, teachers and students.

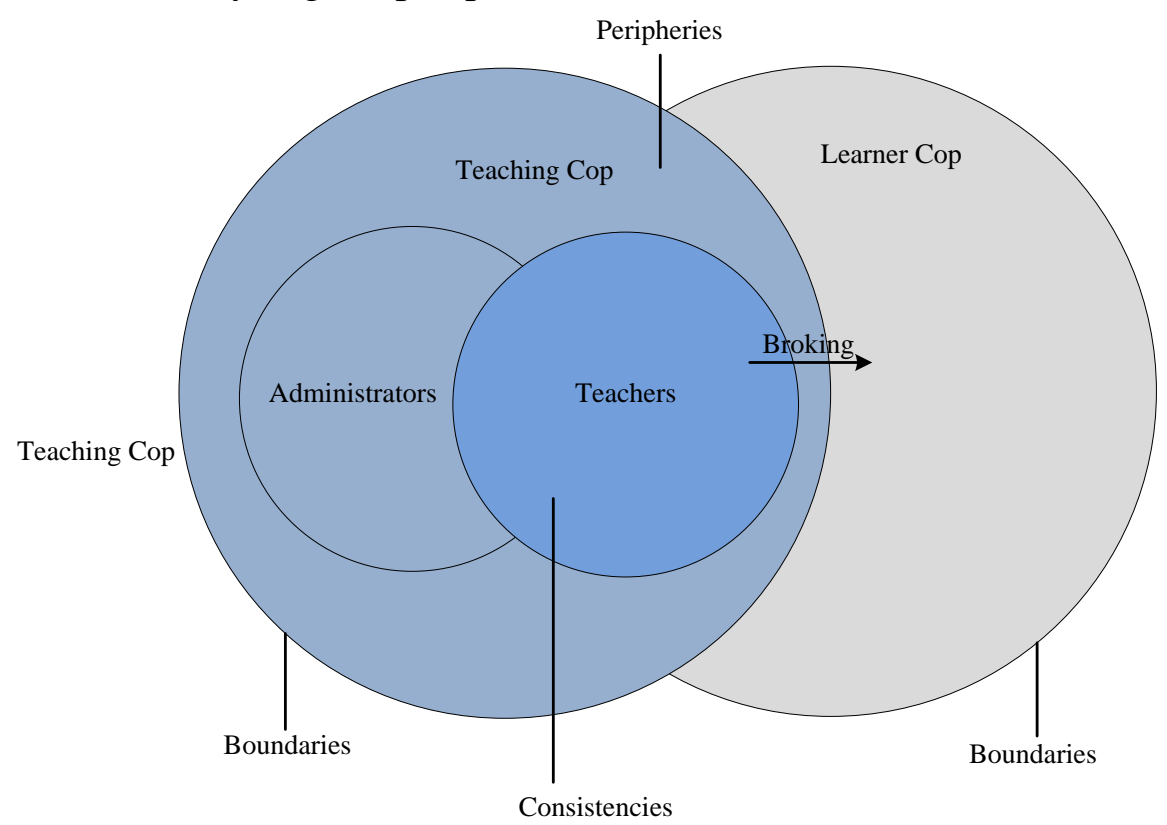

Fig.1 A dual-Cop framework for analyzing the perspectives of the administrator, teachers and students

Lecture style. Generally in the form of lectures or reports, to enable learners to understand or familiar with what is the language learning strategies, language learning strategies which categories, the meaning of language learning strategies and how to learn the flexible use of learning strategies. Lecture Learning Strategies While training can be large, save time, but can not combine specific reading learning activities.

Research style. Seminar learning strategy training is a short-term focus on training, through the lectures, seminars and practical operations organically combine to achieve the purpose of cultivating 
learners' strategic awareness. Learners can discuss and try strategies in a group, but this training pattern requires special time.

Material penetration. The infiltration learning strategy training is to penetrate the training of learning strategies into every unit of the teaching material. There are two forms of penetration that are "hidden" infiltration, the other is "non-hidden" penetration.

Permeation of teaching activities. The teaching strategy of infiltration is to penetrate the training of learning strategies into the whole teaching process of language courses. In this model, the training of learning strategies and language learning and language skills to keep pace. Although the training of learning strategies need to occupy a certain amount of classroom teaching time, but will make learners self-confidence, self-management ability and learning efficiency is enhanced.

A few questions and basic principles to training the reading strategy. The use of reading strategies is closely related to learners' cognitive processes and cognitive abilities. Different age, gender, learning style, language potential, personality characteristics, learning attitude and motivation in the cognitive methods, cognitive processes, cognitive ability and so there is a big difference. Therefore, the choice and design of reading strategies must take full account of the learners in many aspects of the above important factors, because people, because of time, due to serious consideration. Before the effective reading study strategy training, need to pay attention to the following questions:

For what kind of learners choose which reading learning strategies are taught;

Is a unified training for a group of learners, or an individual training method for different learners;

Is a separate training of reading strategies, or training of reading strategies into other language teaching activities;

For some learners to resist the phenomenon of reading learning strategy training, how to solve the learner's awareness of learning strategies;

As some of the learning strategies can be considered immediate training, but most of the learning strategy only through a long period of training to be effective, how to develop appropriate experimental cycle.

On the basis of summarizing previous research achievements and experience, we should carry out the following basic principles when selecting and training language learners' learning strategies:

Intuitive, simple, easy to operate the principle of priority

Learning strategies are closely related to learners' learning tasks and learning objectives Priorities Principle Interesting priorities

Teachers are more familiar with and have a grasp of the training strategy priority principle

Effective learning strategy priorities

General principle. Some learning strategies are only suitable for learning of certain knowledge and skills, while others can be applied to a variety of knowledge and skills

"Learning law, learning no law" principle. Strategy varies from person to person,

We want all the students to understand the strategy is used to better accomplish certain tasks, we choose the strategy, the use of strategy, rather than the strategy of slaves.

Reading strategy training. Clear teacher roles and student responsibilities. First of all, as a teacher, we should reflect on our outdated teaching philosophy, that is, reading strategy training requirements from the "teacher-centered" to "student-centered" teaching methods up. Moreover, we must be aware that the focus of training should also shift from "results" to "processes".

Secondly, it is clear that the learning responsibility of students plays an important role in the beginning of reading strategy training. To establish the "reading strategy to help improve the level of reading" belief. At the beginning of the course to encourage students to set up their own reading goals, will help to establish a student-centered classroom atmosphere. Students should record their own reading goals in short and long term, and self-monitoring and evaluation throughout the strategy training process.

Pre-reading counseling. In each session of the reading strategy training courses can be carried out before the pre-reading counseling activities to mobilize the students the original background knowledge. This is an important step. Specifically, on the subject of reading the article, students can 
orally describe their knowledge and want to further understand the knowledge of teachers through multimedia

Teaching Aids Show relevant pictures or audio-visual information Students can also predict the content of the entire article by looking at the title, illustrations, etc. of the article. Teachers can also encourage students to set up reading goals and implement self-supervision.

The general method of reading strategy training. In the normal classroom teaching in the reading strategy training, four-step training mode is often used:

This stage is described by the teacher to a student to describe a learning strategy, to clarify its essentials, the specific operation and the main role.

The teacher read the strategy to use and manipulate the way. At this stage, reading strategies using the demonstration should be the process of interaction between teachers and students. Students should be informed of what strategies should be used in what context. Subsequent strategy demonstrations should gradually allow students to come in. Teachers can make a demonstration of the use of reading strategies. Fig. 2 presents task-based elements that affect motivation in language learning class.

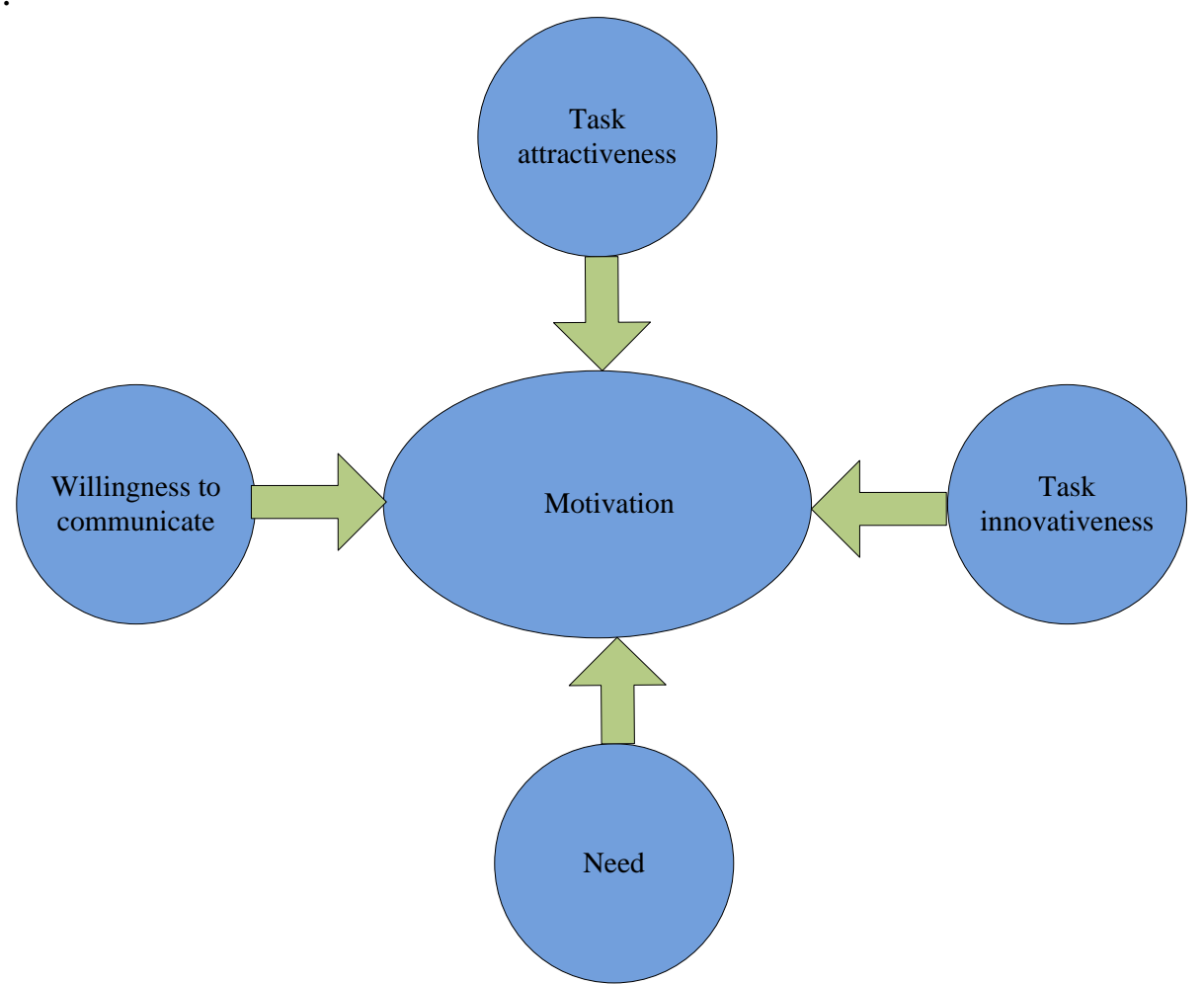

Fig.2 Task-based elements that affect motivation in language learning class

Into a reading task, what kind of reading strategy he used, and a clear summary of the name of the strategy. But this demonstration should be as concise as possible. You can also organize groups or classes to discuss the application of typical reading strategies proposed by students in a typical context. Then the teacher executes.

Training and development, including the provision of language materials for students to show the strategy of special training and further integrated training strategies. At this stage, teachers can learn from exercises to semi-control exercises, to free practice, from single strategy training to strategic integrated training. Teachers can use the students to observe the time of observation,

Supervise and document the extent to which student strategies are used and determine if the next training content is further guidance or more exercises. In the process of reading strategies, teachers should give students feedback in a timely manner. Encouragement is essential for students, but should gradually reduce the ability to improve students' ability to use strategies independently. Students can experience the purpose and meaning of reading strategies is the key to successful strategy acquisition.

Check students' grasp of new strategies. Students can complete the reading task that they have been able to apply a series of reading strategies. However, after reading, students should also be 
encouraged to self-describe, evaluate and discuss the use of the reading strategy in order to design the next experimental operation according to the student's specific situation. Reading a study day, reading reports, seminars, questionnaires is a good way to sum up. Finally, the students should adopt the strategy of reading strategy to give timely results, pay attention to cultivate metacognitive consciousness to promote students 'autonomous learning, improve learners' use of English reading strategies and promote the positive shift of reading strategies

\section{Summary}

The effectiveness of reading teaching is not only the choice of teachers, but it is important not to use the students themselves, especially the learners' learning strategies. This topic is to explore how teachers in the process of reading the students consciously systematic and targeted reading strategy training, and ultimately hope to enable students to learn to read the purpose of learning.

Learning strategies are not natural, nor are they naturally formed. Learning strategies need learners conscious training and training, learning strategy training is the key to the learners themselves, only the learners themselves willing and active participation in learning strategy training, training can be effective, of course, this is inseparable from the teacher's active guidance but , Learning strategy training is not the teacher to other people's learning strategy imposed on the learners, but to introduce the learners to verify the effective learning strategies, so that learners can explore their own personalized learning strategy system, learn how to learn. Learners understand that learning strategies do not mean that they use learning strategies. Only after a conscious learning strategy training, learners can use learning strategies more effectively. Strategic learning is the key to student success. I think strategy learning is the foundation of lifelong learning.

\section{References}

[1] Kangli J. Metacognitive strategy training in EFL learning [J]. Foreign Language World, 2002, 3: 003.

[2] Oxford R, Crookall D. Research on language learning strategies: Methods, findings, and instructional issues[J]. The Modern Language Journal, 1989, 73(4): 404-419.

[3] Zhang L J, Wu A. Chinese senior high school EFL students' metacognitive awareness and reading-strategy use[J]. Reading in a Foreign Language, 2009, 21(1): 37.

[4] Krashen S. We acquire vocabulary and spelling by reading: Additional evidence for the input hypothesis[J]. The modern language journal, 1989, 73(4): 440-464.

[5] Pang J. Research on good and poor reader characteristics: Implications for L2 reading research in China[J]. Reading in a Foreign Language, 2008, 20(1): 1.

[6] Rao Z. Chinese students' perceptions of communicative and non-communicative activities in EFL classroom[J]. System, 2002, 30(1): 85-105.

[7] Zhang L J. Research into Chinese EFL learner strategies: Methods, findings and instructional issues[J]. RELC journal, 2003, 34(3): 284-322.

[8] Lau K L. Reading strategy use between Chinese good and poor readers: a think-aloud study[J]. Journal of Research in Reading, 2006, 29(4): 383-399.

[9] Chamot A U. Language learning strategy instruction: Current issues and research[J]. Annual review of applied linguistics, 2005, 25: 112-130.

[10]Wong J K K. Are the Learning Styles of Asian International Students Culturally or Contextually Based?[J]. International Education Journal, 2004, 4(4): 154-166.

[11] Silva T. Toward an understanding of the distinct nature of L2 writing: The ESL research and its implications[J]. Tesol Quarterly, 1993, 27(4): 657-677.

[12]Cheng L. The key to success: English language testing in China[J]. Language Testing, 2008, 25(1): 15-37.

[13]Rao Z. Reconciling communicative approaches to the teaching of English with traditional Chinese methods[J]. Research in the Teaching of English, 1996: 458-471. 
[14]Gan Z, Humphreys G, Hamp-Lyons L. Understanding successful and unsuccessful EFL students in Chinese universities[J]. The modern language journal, 2004, 88(2): 229-244.

[15]Zhang L J. A dynamic metacognitive systems account of Chinese university students' knowledge about EFL reading[J]. Tesol Quarterly, 2010, 44(2): 320-353.

[16]Jin L, Cortazzi M. English language teaching in China: A bridge to the future[J]. Asia Pacific Journal of Education, 2002, 22(2): 53-64. 